\title{
INCIDENCE OF YERSINIA ENTEROCOLITICA IN FARM ANIMALS AT DAKAHLIA AND KAFR EL-SHEIKH GOVERNORATES
}

\author{
*Ahmed M. Ammar; Amgad A. Moawad \\ **: Emad M. Riad and Fatma M. Elsherbeny \\ *Dept. of Microbiology, Fac. Vet. Med., Zagazig Univ., Egypt \\ ${ }^{* *}$ Dept. of Microbiology, Fac. Vet. Med., Kafrelsheikh Univ., Egypt \\ *** Dept. of Microbiology, Animal Health Research institute, Dokki.,Giza, Egypt.
}

\begin{abstract}
Up to date little is known about incidence of Yersinia enterocolitica in farm animals in Egypt therefore this study was carried out. In this study, 200 samples were collected from diseased animals suffered from diarrhea including cows, buffaloes, sheep and goats were obtained from private and governorate farms at Dakahlia and Kafr El-Sheikh governorates. A total of $23 Y$. enterocolitica strains were recovered. The prevalence rates were 14\%, 14\%, $10 \%$ and $8 \%$ in cows, sheep, Buffaloes and goats respectively. $Y$. enterocolitica isolates were biotyped, 21 isolates out of 23 were belonging to biotype 2 while, only 2 stains were belonging to biotype 1. Serotyping by using the available monovalent antisera, Y.enterocolitica were 19, 2, 2 strains belonging to $O: 3, O: 5$ and $O: 9$ serovars. Serotyping and biotypiny among different isolates revealed that 12 isolates $O: 3 / 2,4$ isolates $O: 5 / 2,2$ isolates $O: 9 / 1$ while 2 isolates $O: 9 / 2$. As regard to the virulence tests, 13 out of tested strains were stable toxin strains, and 17 out of 23 strains were CRMOX producer positive but guinea pig conjunctivitis (Sereny test) was found to be negative for all examined serotypes. The PCR product was visualized after agarose gel electrophoresis. One amplification band of 591 bpwas observed when Y. enterocolitica colonies were used as template for the PCR. The serobiovars of $Y$. enterocolitica strains showing positive for virF gene were $O: 3 / 2(2)$ and $O: 9 / 2(1)$.
\end{abstract}




\section{INTRODUCTION}

Y. enterocolitica is a Gram-negative, facultative anaerobic bacillus belonging to the family Enterobacteriaceae. This organism has a world wide distribution and wide spread in nature (Morris and Feeley, 1976). Because $Y$. enterocolitica grows slowly on ordinary laboratory media, it is easily overgrown by other bacteria (Feng and Weagant, 1994). The most widely used method is the cold enrichment, which requires an incubation period up to 3 weeks, followed by subculturing onto CIN agar and biochemical confirmation (Thisted-Lambertz et al., 1996; Bhaduri et al., 1997 and Hoorfar and Holmvig, 1999). There are over $54 \mathrm{O}$ serotypes of $Y$. enterocolitica but only a few of these have been implicated in human or animal diseases (Bercovier et al., 1980; Kay et al., 1983 and Schiemann and Devenish, 1982). Forty to fifty megadalton plasmid has been described as responsible for the virulence of $Y$. enterocolitica (Gemski et al., 1980). Strains which posses this plasmid exhibit properties, calcium dependancy (Gemski et al., 1980) and congo red absorption (Prpic et al., 1983). A congo red- magnesium oxalate agar medium was developed to detect expression of virulenceassociated calcium dependency and congo red absorption in $Y$. enterocolitica (Riley and Toma, 1989). Virulence of $Y$. enterocolitica was measured by sereny test or mouse lethality test. It was dependant on the presence of $42 \pm 1.1$ megadalton plasmid. PCR methods have proved to be very useful in further classifying $Y$. enterocolitica as virulence that attributed to Yersinia virulence plasmid (PYV) containing virF gene which also imparted calcium dependency on the strain. This gene is present only in pathogenic strain. 
An initial problem with serological studies on $Y$. enterocolitica was the cross-reaction detected between $Y$. enterocolitica $\mathrm{O}: 9$ serotype and Brucella abortus (Ahvonen and Sievers, 1969). Brucella and $Y$. enterocolitica O: 9 have antigenic determinants in common causing cross-reaction which interfere strongly in Brucella serology (Staak et al., 2000). So the present work was carried out for:

1) Prevalence of $Y$. enterocolitica strains from diseased animals suffered from diarrhea including cows, buffaloes, sheep and goats.

2) Biotyping of the isolated strains.

3) Serotyping of the isolated strains.

4) Virulence tests for the isolated $Y$. enterocolitica strains including:

a- Enterotoxin assay.

b- Invasiveness assay.

c- Congo red magnesium oxalate platting.

d- Esculin hydrolysis.

e- Salicin fermentation.

f- Pryrazinamidase production.

5) Polymerase chain reaction technique for detection of virulence factor (virF) gene in isolated $Y$. enterocolitica strain.

6) Sensitivity test for the isolated strains against most common antibiotics. 


\section{MATERIAL AND METHODS}

\section{MATERIALS:}

\subsection{Samples for isolation:}

200 samples were collected from diseased animals suffered from diarrhea including cows, buffaloes, sheep and goats (50 fecal samples for each species) were obtained from private and governorate farms at Dakahlia and Kafrelsheikh governorate. Samples were collected from May 2007 to December 2008.

\subsection{Reference strains of $Y$. enterocolitica $0: 3$ and $0: 9$ :}

They were kindly supplied by Bacteriology Department Animal Health Research, Institute, Dokki, Giza. It used as a positive control strain for PCR.

\subsection{Culture media used:}

\subsubsection{Media for isolation of $Y$. enterocolitica :}

\subsubsection{Solid media:}

- Cefsulodin-irgasan-novpbiocin(C.I.N) medium (Schiemann, 1979): It was prepared by addition of Yersinia Selective Agar base (Oxoid CM653) to Yersinia Selective Supplement (Oxoid,SR109).

- MacConkey's agar medium (Oxoid).

- Nutrient agar (Oxoid).

\subsubsection{Semisolid media:}

-Semisolid Nutrient agar (Oxoid). 


\subsubsection{Media for biochemical identification of $Y$. enterocolitica:}

All media was prepared according to MacFaddin (1976) and Bailey and Scott (1986).

- Triple sugar iron agar (TSI) (Oxoid).

- Simmon's citrate (Oxoid).

- Urea agar base (Oxoid)

- Glucose phosphate broth (Oxoid).

- Nitrate broth (Difco).

- Oxidation fermentation (OF) basal medium (Bio-Merieux).

- Peptone water 1\% (Oxoid).

- Aesculin broth (Farmer et al., 1992):

- Sugar fermentation (Oxoid).

\subsubsection{Media used for virulence tests (Pai and Mors, 1978).}

- Media for production and testing of enterotoxin.

- Brain heart infusion broth (Oxoid): used for Sereny test.

- Tryptone soya agar (Oxoid): used for Sereny test.

- 5\% sheep blood agar used for CRMOX.

- Congo red magnesium oxalate agar (CRMOX) medium (Riley and Toma, 1989).

- Aesculin agar: used for aesculin hydrolysis.

- Phenol red peptone water containing $0.5 \%$ of salicin: used for salicin fermentation test.

- Media used for pyrazinamidase test (Kandolo and Wsuiters, 1985). 


\subsection{Reagents and Solutions:}

- 3\%hydrogen peroxide solution, used for catalase test.

- $1 \%$ tetramethyl-P-phenyliamine dihydrochloride solution used for oxidase test.

- 40\% urea solution (Oxoid, SR20) used for urease test.

- $0.02 \%$ methyl red solution used for methylred test.

- Kovac's reagent, for indole test.

$-10 \%$ lactose for OF test.

- $0.8 \%$ sulfanilic acid in $5 \mathrm{~N}$ acetic acid and $0.5 \%$ alpha naphthylamine in $5 \mathrm{~N}$ acetic acid used for nitrate reducyion test.

- Paraffin oil for decarboxylase and OF tests.

- 5\% alpha naphthol in absolute ethyl alcohol and $40 \%$ potassium hydroxide for voges proskauer test.

- $1 \% \mathrm{wt} / \mathrm{vol}$ freshly prepared ferrous ammonium sulphate(aqueous) solution: used for pyrazinamidase test.

\subsection{Antibacterial discs used for antibacterial sensitivity test:}

12 Antibacterial discs from oxoid containing the following chemotherapeutics:

Amikacin $(30 \mu \mathrm{g})$, ampicillin $(10 \mu \mathrm{g})$, Chloramphenicol $(30 \mu \mathrm{g})$, ofloxacin $(10 \mu \mathrm{g})$, streptomycin $(10 \mu \mathrm{g})$, neomycin $(10 \mu \mathrm{g})$, gentamycin $(10 \mu \mathrm{g})$, erythromycin $(15 \mu \mathrm{g})$, tetracycline $(30 \mu \mathrm{g})$, cefotaxime $(30 \mu \mathrm{g})$, colistine sulphate $(10 \mu \mathrm{g})$, and sulphamethoxazol-trimethoprim $(1.25+5.75 \mu \mathrm{g})$, 


\section{Methods:}

\subsection{Collection of samples:}

200 fecal samples from diarrheic animals and received in aseptic bag to lab immediately.

\subsection{Isolation of $Y$. enterocolitica:}

2.2.1. Direct plating: (Nilehn, 1969; Schiemann, 1979 and Fredriksson-Ahomaa et al., 1999).

Fecal swabs were streaked directly onto CIN and MacConkey's agar plates and incubated at $30^{\circ} \mathrm{C}$ for $18-24 \mathrm{~h}$. Lactose negative colonies on MacConkey's agar were streaked onto CIN agar and incubated at $30^{\circ} \mathrm{C}$ for $18-24 \mathrm{~h}$.

\subsubsection{Cold enrichment: (Adesiyun et al., 1992 and Fredriksson-} Ahomaa et al., 1999).

One loopful of fecal sample was incubated into $5 \mathrm{ml}$ sterile phosphate buffered saline ( $\mathrm{pH} 7.6)$ tubes. The tubes were enriched at $4^{\circ} \mathrm{C}$ (in a refrigerator) for one month and subcultured weekly at intervals one, two, three and four weeks onto CIN and MacConkey's agar which were incubated at $30^{\circ} \mathrm{C}$ for $18-24 \mathrm{~h}$. Lactose negative colonies on MacConkey's agar were streaked onto CIN agar and incubated at $30^{\circ} \mathrm{C}$ for $18-24 \mathrm{~h}$. Suspected colonies were picked up and subcultured onto nutrient agar Plates to confirm its purity, and then transferred (as well as reference strain) to nutrient slopes for maintenance till they were screened. 
2.3. Identification of the Y. enterocolitica isolates (Nilehn, 1969a and Pianetti et al.,1990):

\subsubsection{Morphological and Culture examination.}

Pure cultures were prepared from all suspected colonies, shape, size, type of colonies either lactose fomenter or non lactose fomenter onto MacConkey's agar.

\subsubsection{Biochemical identification: (Bercovier and Mollaret, 1984):}

The suspected colonies were biochemically identified using the following tests:

Oxidase test, Catalase test, sugar fermentation test, Hydrogen sulphide production test using TSI agar, Urease test, Citrate utilization test ( at 25 and $37^{\circ} \mathrm{C}$ ), Indole production test, Methyl red test (at 25 and $37^{\circ} \mathrm{C}$ ), Voges proskauer ( at 25 and $37^{\circ} \mathrm{C}$ ), Nitrate reduction test, Oxidation fermentation test and Aesculin hydrolysis test.

\subsection{Biotyping of $Y$. enterocolitica isolates (Nilehn, 1969a):}

Biotyping according to results of biochemical tests as shown in table 1:

Table (1): Biotyping of Y. enterocolitica using different biochemical tests.

\begin{tabular}{||l||c|c|c|c|c||}
\hline \multicolumn{1}{|c||}{ Biochemical reactions } & \multicolumn{5}{c||}{ Biovars } \\
\cline { 2 - 7 } & $\mathbf{1}$ & $\mathbf{2}$ & $\mathbf{3}$ & $\mathbf{4}$ & $\mathbf{5}$ \\
\hline \hline Salicin(acid) & + & - & - & - & - \\
\hline Indole & + & - & - & - & - \\
\hline Lactose (O-F) & + & + & - & - & - \\
\hline Xylose(acid) & + & + & + & - & - \\
\hline Nitrate reduction & + & + & + & + & - \\
\hline Trehalose(acid) & + & + & + & + & - \\
\hline Voges proskauer & + & + & + & + & - \\
\hline Sorbose(acid) & + & + & + & + & - \\
\hline Sorbitol(acid) & + & + & + & + & - \\
\hline Sucrose(acid) & + & + & + & + & - \\
\hline \hline
\end{tabular}

+ : Positive

-: Negative

$\overline{\overline{\text { Kafrelsheikh Vet. Med. J. Vol. } 8 \text { No. } 2 \text { (2010) }}}$ 
2.5. Serotyping of the isolates (Winblad at al., 1966 and Winblad, 1967):

The isolates were serotyped using the available monovalent antisera; O: 3, O: 5, O: 8 and O: 9 by slide agglutination test.

\subsubsection{Virulence test:}

Reference strain was used as a positive control as well as all Y.enterocolitica isolates.

\subsubsection{Enterotoxin assay:}

The ability to produce heat stable enterotoxin was assayed by the infant mouse test (Pai and Mors, 1978 and Robins-Browne et al. 1993).

2.5.3. Infant mouse assay (Pai and Mors, 1978 and Schiemann and Devenish, 1982):

$0.1 \mathrm{ml}$ of culture filtrate of identified Y.enterocolitica strain was introduced through abdominal wall into milk filled stomach of each three mice which were $1-2$ days old. After 4 hours, the mice were killed and the entire intestine was removed. The ratio between the intestine and the remaining body weight were calculated. A ratio greater than 0.083 was taken as positive for enterotoxin.

\subsubsection{Invasiveness assay:}

Test was done in guinea pig eye model "Sereny test" according to Schiemann and Devenish, 1982 and Kay et al., 1983.

\subsubsection{Congo red magnesium oxalate (CRMOX):}

It was used for detection of pathogenic $Y$. enterocolitica strain (Riley and Toma, 1989). 
Tested strains was first grown on blood agar plates (5\% sheep blood) at $22^{\circ} \mathrm{C}$ for $18 \mathrm{~h}$ and then plated onto CRMOX medium and incubated for $24 \mathrm{hrs}$ at $36^{\circ} \mathrm{C}$. Strains were CRMOX negative if only large colorless colonies were present.

Positive strains (CRMOX) always produce small red colonies.

\subsubsection{Aesculin hydrolysis (Farmer et al.,1992):}

All Y. enterocolitica isolates were inoculated into aesculin broth and incubated at $25^{\circ} \mathrm{C}$. results recorded daily up to 7 days. Strains that hydrolysis aesculin show blackening of the media.

\subsection{PCR for detection of vir $F$ gene(Bhaduri et al.,1997):}

Ten Y.enterocolitica isolates were evaluated for the presence of vir $F$ gene with PCR assay. All selected isolates showing the virulence characteristics. The PCR technique was carried out at Biotechnology Lab., Fac.Vet.Med ., Cairo University.

Field Y.enterocolitica strains and DNA extraction method (Nakajima et al.1992):

A suspension of Y.enterocolitica isolates having $108 \mathrm{CFU} / \mathrm{ml}$ was prepared I TE buffer by adjusting its turbidity with McFarland standards. $10 \mu 1$ of this suspension was put onto thin walled microtubes and was placed onto boiling water for 10 min followed by plunging into an ice bath. One $\mu$ l of supernatant was used directly for amplification without any further processing. 
Primer selection and preparation (Bhaduri et al.,1997):

The vir $F$ gene from Y.enterocolitica has been used. PCR was designed to amplify a 591-bp fragment (nucleotide region 430-1020) of the vir $F$ gene encoded by plasmid PYV.

Oligonucleotide primer pair used were 5'- TCA TGG CAG AAC AGT CAG-3' and 5'-ACT CAT CTT ACC ATT AAG AAG-3' for amplification of vir $F$.

\section{(PCR) DNA amplification procedure:}

DNA samples were amplified in a total of $50 \mu \mathrm{l}$ of amplification mixture.

All samples were overlaid with $50 \mu \mathrm{l}$ of mineral oil, PCR was performed on a PTC-100 programmable thermal controller.

PCR cycling protocol (Bhaduri et al., 1997):

Amplification cycles were as follows: initial denaturation step of 5 $\mathrm{mm}$ at $95^{\circ} \mathrm{C}$ followed by 30 cycles of $94^{\circ} \mathrm{C}$ for $30 \mathrm{sec}$ (Denaturation) 60 ${ }^{\circ} \mathrm{C}$ for $30 \mathrm{sec}$ (Annealing) and $70^{\circ} \mathrm{C}$ for $1 \mathrm{~min}$ (Extension). A positive and Negative control ( no template) were included in each PCR run.

\section{Analysis of PCR product using Agarose Gel Electrophoresis:}

$1.5 \%$ agarose gel was prepared in TAE IX buffer in the microwave after complete dissolving of the agarose in the buffe. Ethidium bromide was added in $0.5 \mathrm{mg} / \mathrm{ml}$ and mixed thoroughly. The gel left to become warm at room temperature. The tray was prepared and the comb 0.5-1 $\mathrm{mm}$ was placed above the tray in a suitable distance. 


\section{7. in Vitro antibacterial sensitivity test by disk diffusion technique according to Finegold and Martin, 1982. As shown in table2.}

Table (2): Antibacterial sensitivity in relation to the zone of inhibition interpreted by the manufacturing company (Oxoid).

\begin{tabular}{|l||c||c|c||}
\hline \multicolumn{1}{|c||}{ Antibacterial drug } & \multirow{2}{*}{ Disc content } & \multicolumn{2}{c||}{ Diameter of inhibition zone } \\
\cline { 2 - 4 } & & Resistant & Sensitive \\
\hline \hline Amikacin & $30 \mu \mathrm{g}$ & $14-16$ & 16 or more \\
\hline Ampicillin & $10 \mu \mathrm{g}$ & 13 or less & 14 or more \\
\hline Cefotaxime & $30 \mu \mathrm{g}$ & 15 or less & 16 or more \\
\hline Chloramphenicol & $30 \mu \mathrm{g}$ & 17 or less & 18 or more \\
\hline Ofloxacin & $10 \mu \mathrm{g}$ & 15 or less & 16 or more \\
\hline Streptomycin & $10 \mu \mathrm{g}$ & 14 or less & 15 or more \\
\hline Neomycin & $30 \mu \mathrm{g}$ & 16 or less & 17 or more \\
\hline Gentamycin & $10 \mu \mathrm{g}$ & 14 or less & 15 or more \\
\hline Erythromycin & $15 \mu \mathrm{g}$ & 17 or less & 18 or more \\
\hline Tetracycline & $30 \mu \mathrm{g}$ & 18 or less & 19 or more \\
\hline Colistine sulphate & $10 \mu \mathrm{g}$ & 8 or less & 11 or more \\
\hline Trimethoprim- sulphamethoxazol & $1.25+5.75 \mu \mathrm{g}$ & 15 or less & 16 or more \\
\hline \hline
\end{tabular}

\section{RESULTS}

\subsection{Prevalence rate of $Y$. enterocolitica in the examined animal species:}

Table(3): The prevalence rate of $Y$. enterocolitica in diseased animals suffered from diarrhea.

\begin{tabular}{|c|c|c|c|c|}
\hline \multirow{2}{*}{ Animal species } & \multirow{2}{*}{ Type of samples } & \multirow{2}{*}{ No. of cases } & \multicolumn{2}{|c|}{ Positive ones } \\
\hline & & & No. & $\%$ \\
\hline Cows & Fecal & 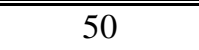 & $\overline{7}$ & 14 \\
\hline Buffaloes & Fecal & 50 & 5 & 10 \\
\hline Sheep & Fecal & 50 & 7 & 14 \\
\hline Goats & Fecal & 50 & 4 & 8 \\
\hline Total & & 200 & 23 & 11.5 \\
\hline
\end{tabular}

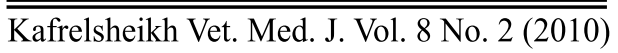


Incidence Of Yersinia Enterocolitica In Farm Animals At ...

Table (4): Comparison between direct plating and cold enrichment techniques for isolation of $Y$. enterocolitica from 200 samples collected from different animals.

\begin{tabular}{|c||c||c||c|c||c|c||}
\hline \multirow{2}{*}{ Animal species } & $\begin{array}{c}\text { Type of } \\
\text { samples }\end{array}$ & No. of samples & \multicolumn{2}{|c||}{$\begin{array}{c}\text { Positive by } \\
\text { direct plating }\end{array}$} & \multicolumn{2}{c|}{$\begin{array}{c}\text { Positive by } \\
\text { enrichment }\end{array}$} \\
\cline { 3 - 7 } & & & No & $\%$ & No & $\%$ \\
\hline \hline Cows & Fecal & 50 & - & - & $\mathbf{7}$ & $\mathbf{1 4}$ \\
\hline Buffaloes & Fecal & 50 & $\mathbf{1}$ & $\mathbf{2}$ & $\mathbf{5}$ & $\mathbf{1 0}$ \\
\hline Sheep & Fecal & 50 & - & - & $\mathbf{7}$ & $\mathbf{1 4}$ \\
\hline Goats & Fecal & 50 & - & - & $\mathbf{4}$ & $\mathbf{8}$ \\
\hline \hline Total & & $\mathbf{2 0 0}$ & $\mathbf{1}$ & $\mathbf{2}$ & $\mathbf{2 3}$ & $\mathbf{1 1 . 5}$ \\
\hline \hline
\end{tabular}

\subsection{Identification of $Y$. enterocolitica isolates (23) morphologically,} colonial characters, motility and Biochemically:

Gram stained films showed small coccoid, gram negative bacilli, non sporulated, non capsulated and arranged singly or in short chains or heaps.On CIN agar Y.enterocolitica colonies were approximately 0.5$2 \mathrm{~mm}$ in diameter after $18-24 \mathrm{hr}$ at $30^{\circ} \mathrm{C}$. they were characterized by dark red center surrounded by an outer translucent zone" Bulls eye". On MacConkey agar, colonies were pale non lactose fermenter, pinpoint or flat colonies, translucent and $1 \mathrm{~mm}$ in diameter after $24 \mathrm{hr}$ at $30^{\circ} \mathrm{C}$.On nutrient agar purified colonies were circular, smooth, low convex, 1$2 \mathrm{~mm}$ in diameter, translucent, with glistening surface and entire or slightly crenated edge after $24-48$ hours at $25^{\circ} \mathrm{C}$. All isolates were found to be motile at $25^{\circ} \mathrm{C}$ and non motile at $37^{\circ} \mathrm{C}$. Biotyping depending on reactions against different biochemical tests. 
Ahmed M. Ammar et., al.

Table (5): Biovars of $Y$. enterocolitica strains isolated from the examined animal species:

[Percentage Of biotypes were calculated in relation to number of isolates (23)]

\begin{tabular}{|c|c|c|c|c|c|c|c|}
\hline \multirow{2}{*}{$\begin{array}{l}\text { Animal } \\
\text { species }\end{array}$} & \multirow{2}{*}{$\begin{array}{l}\text { Type of } \\
\text { samples }\end{array}$} & \multirow{2}{*}{$\begin{array}{c}\text { No. of } \\
\text { samples }\end{array}$} & \multirow{2}{*}{$\begin{array}{c}\text { No. of } \\
\text { isolates }\end{array}$} & \multicolumn{4}{|c|}{ Biotype } \\
\hline & & & & No.1 & $\%$ & No. 2 & $\%$ \\
\hline Cows & Fecal & 50 & 7 & 1 & 14.3 & 6 & 85.7 \\
\hline Buffaloes & Fecal & 50 & 5 & - & - & 5 & 100 \\
\hline Sheep & Fecal & 50 & 7 & 1 & 14.3 & 6 & 85.7 \\
\hline Goats & Fecal & 50 & 4 & - & - & 4 & 100 \\
\hline Total & & 200 & 23 & 2 & 8.9 & 21 & 91.1 \\
\hline
\end{tabular}

\subsection{Identification of $Y$. enterocolitica isolates (23) serologically:}

Using the available monovalent antisere O: 3, O: 5, O: 8 and O: 9 by slide agglutination test.

Table (6): Serotypes of $Y$. enterocolitica strains isolated from different examined animal species:

\begin{tabular}{|c|c|c|c|c|c|c|c|c|c|}
\hline \multirow{3}{*}{$\begin{array}{l}\text { Type of } \\
\text { samples }\end{array}$} & \multirow{3}{*}{$\begin{array}{l}\text { No. of } \\
\text { isolates }\end{array}$} & \multicolumn{4}{|c|}{ Serovars } & & & & \\
\hline & & \multicolumn{2}{|c|}{ O: 3} & \multicolumn{2}{|c|}{ O: 5} & \multicolumn{2}{|c|}{ O: 9} & \multicolumn{2}{|c|}{ O: 8} \\
\hline & & No. & $\%$ & No. & $\%$ & No. & $\%$ & No. & $\%$ \\
\hline Fecal & 23 & 15 & 82.6 & 4 & 8.6 & 4 & 8.6 & 0 & 0 \\
\hline
\end{tabular}

$\overline{\overline{\text { Kafrelsheikh Vet. Med. J. Vol. } 8 \text { No. } 2 \text { (2010) }}}$ 
Incidence Of Yersinia Enterocolitica In Farm Animals At ...

3.3. Distribution of $Y$. enterocolitica serotypes and Biotypes in different examined samples:

Table (7): Serotyping and biotyping of $Y$. enterocolitica strains among examined animal species:

\begin{tabular}{|c||c||c||c|c|c|c||}
\hline \multirow{2}{*}{$\begin{array}{c}\text { Animal } \\
\text { species }\end{array}$} & \multirow{2}{*}{$\begin{array}{c}\text { Type of } \\
\text { samples }\end{array}$} & \multirow{2}{*}{$\begin{array}{c}\text { No. of } \\
\text { isolates }\end{array}$} & \multicolumn{5}{|c||}{ Serobiovars } \\
\cline { 5 - 8 } & O: $\mathbf{3 / 2}$ & O: $\mathbf{3 / 2}$ & O: 9/1 & O: 9/2 \\
\hline \hline Cows & Fecal & 7 & $\mathbf{5}$ & - & $\mathbf{1}$ & $\mathbf{1}$ \\
\hline Buffaloes & Fecal & 5 & $\mathbf{3}$ & $\mathbf{1}$ & - & $\mathbf{1}$ \\
\hline Sheep & Fecal & 7 & $\mathbf{4}$ & $\mathbf{2}$ & $\mathbf{1}$ & - \\
\hline Goats & Fecal & 4 & $\mathbf{3}$ & $\mathbf{1}$ & - & - \\
\hline Total & & 23 & $\mathbf{1 5}$ & $\mathbf{4}$ & $\mathbf{2}$ & $\mathbf{2}$ \\
\hline
\end{tabular}

\subsection{Virulence tests:}

Table (8): Relation between virulence factors and $Y$. enterocolitica serobiovars.

\begin{tabular}{|c|c|c|c|c|c|c|c|c|c|c|}
\hline \multirow{3}{*}{ Virulence test } & \multicolumn{8}{|c|}{ Y. enterocolitica serobiovars } & \multirow{2}{*}{\multicolumn{2}{|c|}{ Total }} \\
\hline & \multicolumn{2}{|c|}{$0: 3 / 2(15)$} & \multicolumn{2}{|c|}{$0: 5 / 2(4)$} & \multicolumn{2}{|c|}{$0: 9 / 1(2)$} & \multicolumn{2}{|c|}{$0: 9 / 2(2)$} & & \\
\hline & No. & $\%$ & No. & $\%$ & No. & $\%$ & No. & $\%$ & No. & $\%$ \\
\hline ST & 11 & 73.3 & 2 & 50 & 0 & 0 & 2 & 100 & 15 & 65.2 \\
\hline CRMOX & 13 & 86.6 & 4 & 100 & 0 & 0 & 2 & 100 & 19 & 82.6 \\
\hline GPC & 0 & 0 & 0 & 0 & 0 & 0 & 0 & 0 & 0 & 0 \\
\hline $\mathrm{AH}$ & 0 & 0 & 0 & 0 & 2 & 100 & 0 & 0 & 2 & 8.7 \\
\hline SF & 0 & 0 & 0 & 0 & 2 & 100 & 0 & One: & 2 & 8.7 \\
\hline PP & 0 & 0 & 0 & 0 & 2 & 100 & 0 & 0 & 2 & 8.7 \\
\hline
\end{tabular}

ST: Heat stable enterotoxin production.

GPC: Guinea pig conjunctivitis( sereny test).

SF: Salicin fermentation
CRMOX: Congo red magnesium oxalate.

AH: Aesculin hydrolysis

PP: Pyrazinamidase production

$\overline{\text { Kafrelsheikh Vet. Med. J. Vol. } 8 \text { No. } 2 \text { (2010) }}$ 


\subsection{Results of PCR for detection of vir $F$ gene:}

Ten selected $Y$. enterocolitica isolates of serotype O: $3 / 2$ (8 isolates), O: 9/2(2 isolates) were subjected toPCR technique together with reference strain.

As shown in photo (1), the PCR product visualized after agarose gel electrophoresis was specific for the virulent gene of $Y$. enterocolitica (vir F), lane 3,4 (field strains) and lane 2 (reference strain).

One amplified band of 591-bp was observed when the DNA of $Y$. enterocolitica colonies were used as template for PCR. The serobiovar of $Y$. enterocolitica strains showing positive for vir $F$ gene were $O$ : $3 / 2$ (lane 3) and O: 9/2 (lane 4) while the lane 2 was the positive control(serobiovar O: 3/2). 


\section{0}

1600

1200

800

650

200

1

2

3

Photo (1): Result of PCR assay

Lane 2: Reference strain (Control 0:3/2).

Lanes 3: Field strain (O:3/2)

Lanes 4: Field strain (0:9/2)

$\overline{\overline{\text { Kafrelsheikh Vet. Med. J. Vol. } 8 \text { No. } 2 \text { (2010) }}}$ 
3.6. Correlation between virulence tests and PCR results for the presence of $\operatorname{vir} F$ gene:

Table (9): Virulence characteristics and PCR results for the presence of vir F gene of Y. enterocolitica isolates.

\begin{tabular}{|c||c||c||c||c||c||c||c||c||}
\hline $\begin{array}{c}\text { Phenotype } \\
\text { tests and } \\
\text { virulence gene }\end{array}$ & O: $\mathbf{3 / 2}$ & O: $\mathbf{9 / 2}$ & $\mathbf{O} \mathbf{3 / 2}$ & $\mathbf{O} \mathbf{5 / 2}$ & $\mathbf{O : ~ 9 / 2}$ & $\mathbf{O : ~ 3 / 2}$ & O: $\mathbf{5 / 2}$ & $\begin{array}{c}\text { Total } \\
\text { positive }\end{array}$ \\
\hline \hline ST & + & + & + & + & + & - & - & $8(80 \%)$ \\
\hline CRMOX & + & + & + & + & + & + & + & $10(100 \%)$ \\
\hline GPC & - & - & - & - & - & - & - & $0(0 \%)$ \\
\hline AH & - & - & - & - & - & - & - & $0(0 \%)$ \\
\hline SF & - & - & - & - & - & - & - & $0(0 \%)$ \\
\hline PP & - & - & - & - & - & - & - & $0(0 \%)$ \\
\hline virFgene & + & + & - & - & - & - & - & $3(30 \%)$ \\
\hline
\end{tabular}

ST: Heat stable enterotoxin production.

GPC: Guinea pig conjunctivitis ( sereny test).

SF: Salicin fermentation
CRMOX: Congo red magnesium oxalate.

AH: Aesculin hydrolysis

PP: Pyrazinamidase production

\subsection{Results of antibiotic sensitivity tests of $Y$. enterocolitica isolates:}

Table (10): Sensitivity tests of $Y$. enterocolitica isolates against different antibiotics.

\begin{tabular}{|c||c|c||c|c||}
\hline \multirow{2}{*}{ Chemotheraputic agent } & \multicolumn{2}{|c|}{ Sensitive } & \multicolumn{2}{c|}{ Resistant } \\
\cline { 2 - 5 } & No. & $\mathbf{\%}$ & No. & \% \\
\hline \hline Amikacin & 23 & 100 & - & 0.0 \\
\hline Ampicillin & 0.0 & 0.0 & 23 & 100 \\
\hline Cefotaxime & 20 & 78.6 & 3 & 21.4 \\
\hline Chloramphenicol & 15 & 53.6 & 8 & 46.4 \\
\hline Colistin sulphate & 10 & 35.7 & 13 & 64.2 \\
\hline Erythromycin & 2 & 7.1 & 21 & 92.9 \\
\hline Gentamycin & 23 & 100 & - & 0.0 \\
\hline Neomycin & 15 & 53.6 & 8 & 46.4 \\
\hline Ofloxacin & 18 & 71.4 & 5 & 28.5 \\
\hline Tetracycline & 16 & 57.1 & 7 & 42.9 \\
\hline Streptomycin & 14 & 50 & 9 & 50 \\
\hline Trimethoprim- sulphamethoxazol & 13 & 42.9 & 10 & 42.9 \\
\hline
\end{tabular}

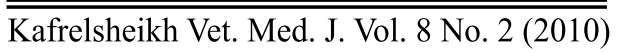




\section{DISCUSSION}

$Y$. enterocolitica is capable of causing a variety of diseases in both animals and human; gastroenteritis, septicaemia, terminal ileitis closely resembling appendicitis (Ahovonen, 1972 and Mittal and Tizarcl, 1981). In the present study, the prevalence rates of $Y$. enterocolitica recovered from 200 samples collected from diseased animals suffered from diarrhea were $14 \%, 10 \%, 14 \%$ and $8 \%$ in cows, buffaloes, sheep and goats respectively. Meanwhile, the same findings were recorded in Egypt by Tanios (1994) who revealed that 34 animals carrying $Y$. enterocolitica with prevalence rate of $3.2 \%$ but for examined animals $(2.5 \%)$ in cows, (3\%) in buffaloes and (3\%) in sheep. In another study Ahmed (1998) found that $Y$. enterocolitica have a role for inducing enteric disease in cattle, sheep and goats. It was isolated from 16 samples (8\%) from buffaloes, 4 samples (2\%) from cows, 3 samples (1.5\%) from goats.Nearly similar results were recorded by Ahvonen et al., (1973) and Alonso et al.,(1979). The rates of isolation of $Y$. enterocolitica have varied widely within and between countries possibly because of true differences in the prevalence of $Y$. enterocolitica infection. However, the isolation technique has been reported to have a significant effect on the rates obtained (Okoroafor et al., 1988 and Ahmed, 2003).

Our study referred that one sample $(0.5 \%)$ was positive to $Y$. enterocolitica by direct plating technique and 23 samples (11.5\%) were positive by cold enrichment method. Our findings agreed with Davey et al., (1983) and Zheng (1987) who recorded that cold enrichment technique increase the frequency of isolation of $Y$. enterocolitica.As well as Thisted-Lambertz et al.,(1996), Bhaduri et al., (1997), Hoorfar and Kafrelsheikh Vet. Med. J. Vol. 8 No. 2 (2010) 
Holmvig (1999) stated that most widely used method was the cold enrichment with an incubation period up to 3 weeks followed by subculturing onto CIN agar. Greenwood and Hooper (1988), Fukushima and Gomyoda(1986) and Hussein et al., (2001), concluded that selective enrichment with Lurria-Bertani- Bile salts Irgasan(LBBSI) produced the highest recovery rate $(63 \%)$ of $Y$. enterocolitica isolates, when compared with cold enrichment (52\%) and direct plating on CIN agar alone (43\%).

The biochemical variability within this group encouraged the development of different biotyping schemes (Nilehn, 1969b, Knapp and Thai, 1973, Brenner et al., 1977 and Winbhul, 1967). According to Nilehn (1969a), the biotyping of $Y$. enterocolitica were done using different biochemical tests including Aesculin hydrolysis, Salicin fermentation, Indole, Lactose (O-F), Xylose, Nitrate reduction, Trehalose, Ornithine decarboxylase, Voges proskauer, Sorbose, Sorbitol and Sucrose fermentation. Through this study the majority of strains (21) were biotype 2 . While only 2 stains were biotype 1 . In both cows and sheep, 6 isolates were biotype 2 and only one was biotype1, meanwhile all strains isolated from buffaloes and goats were of biotype2. The same result of biotyping were recorded by Fukushima et all (1993), Tanios (1994), Zamora et al., (1997), Filetici et al., (2000) and Ahmed (2003) who isolated $26 Y$. enterocolitica strains from cattle, sheep and goats. They biotyped into biotype 1 ( 24 isolates) and biotype 2 ( 2 isolates).

As regard to seological identification by using the available monovalent antisera O: 3, O: 5, O:8 and O: 9 and by slide agglutination test; the result of serotyping of the $23 \mathrm{Y}$. enterocolitica strains were as the 
following: 15, 4 and 4 strains were serotyped O: 3, O: 5 and O:9 serovars respectively, serotype O: 3 was the most prevalent serotype recovered in the present study. These results were agree with Pedersen (1979), Christensen (1980), Tauxe et al., (1987) and Bottone (1997) concluded that O: 3 serotype was one of the important human gastrointestinal pathogens. On the other hand, Ahmed (2003) and Falcao et al., (2004) isolated Y. enterocolitica serotype O: 3 (92.5\%) and O: 9 (7.69\%) from examined cattle, sheep. The distribution of $Y$. enterocolitica strains in different animal species were four different bioserovars of $Y$. enterocolitica. O: $3 / 2$ serobiovar was the most prevalent one $(65.2 \%)$. The other serobiovars recovered were O: 5/2, O: $9 / 1$ and O: $9 / 2$ with a prevalence rates of $17.4 \%, 8.7 \%$ and $8.7 \%$ respectively. These results go parallel with that obtained by Corbel et al.,(1990), Fantasia et al.,(1993), Zheng and Xie (1996) and Ahmed(2003) identified serobiovars $O: 3 / 2$ and $O: 9 / 1$ in $92.3 \%$ and $7.69 \%$ respectively in examined cattle, sheep and goats. The presence of the gene vir $F$ (virulence factor) confirms the presence of virulence plasmid, which is essential for bacterial pathogenesis (Cornelis, 1994).In the present study, $23 Y$. enterocolitica strains of different bioserovars were examined for seven different virulence tests, Heat stable enterotoxin(ST) was produced by $62.5 \%$ of examined strains, regarding toCRMOX test, all isolates of O: $5 / 2$ and O: $9 / 2$ were positive, but negative for O:9/1, Sereny test was found to be negative for all examined serotypes and the organism can't be reisolated from the animals 7 days after inoculation. There was $100 \%$ agreement between Aesculin hydrolysis, Salicin fermentation and Pyrazinamidase production for the examined $Y$. enterocolitica strains. 
The combined use of CRMOX, Sal/Esc and Pyz tests provides a method for accurately differentiating between pathogenic and non pathogenic $Y$. enterocolitica strains. Also, our results revealed that the isolated Y. enterocolitica can be able to produce heat stable enterotoxin, showed an agreement with those reported by Pai and Mors (1978), Delor et al., (1990), Delor and Cornell's (1992) and Robins-Browne et al., (1993) investigated 28 clinical isolates of $Y$. enterocolitica for their abilities to produce heat stable enterotoxin, while the same findings were reported by Bin Kun et al., (1994) who studied acute yersniosis in sheep due to $Y$. enterocolitica toxin, that all isolates producing thermostable toxins capable of producing bleeding from capillaries, myocardial degeneration and death.

In regard to sereny test, Brewer and Corbel (1983) agree with the results obtained that $Y$. enterocolitica isolates from abortion or enteritis cases of cattle and lambs can't produce any sign of local or general disturbance after conjunctival instillation and the organism can't be reisolated from the animals 7 days after instillation.

The first PCR method used for detection of pathogenic $Y$. enterocolitica was developed by Wren and Tabaqchali 1990. Pathogenic strains of $Y$. enterocolitica are characterized by a chromosomally encoded ability to invade cultured mammalian cells and the presence of a virulence plasmid, PYV, that may facilitate bacterial survival within host tissues (Miller and Falkow, 1988 and Isberg, 1990). In the present study, ten selected $Y$. enterocolitica isolates of serotype $O: 3 / 2$ and $O: 9 / 2$ were subjected to PCR technique together with reference strain. It was specific for the virulent gene of $Y$. enterocolitica (vir $F$ ). Lane 3 and 4 
(field strains) and Lane 2 (reference strain). One amplified band of 591 bp was observed when the DNA of $Y$. enterocolitica colonies were used as template for PCR. The serobiovars of $Y$. enterocolitica strains showing positive for vir $F$ gene were O: 3/2 (Lane3) and O:9/2 (Lane4). While the lane 2 was the positive control (serobiovar O: 3/2). These results were agree with that obtained by Kappariid (1991) who stated that the best characterized virulence factor for $Y$. enterocolitica encoded by the vir $F$ gene mapped to a $70 \mathrm{Kbp}$ plasmid.

In the present work the DNA of $Y$. enterocolitica was extracted by simple boiling for colonies of the organism for $10 \mathrm{~min}$, then followed by cooling. The same method was used by Sritharan and Barker (1991) and Kocagoz et al., (1993) for DNA preparation. They suggested that, the preparation of DNA by just boiling rather than enzymatic lysis followed by phenol-chloroform extraction was better foe amplification with PCR, on the other hand, Thisted lambertz et al., (1996) described that PCR method provided results within $24 \mathrm{~h}$ when nested PCR was used. Besides increasing the sensitivity, the PCR also ensures higher specificity. Several measures have been introduced in order to prevent such contamination. Many blank reactions must be involved in the PCR assay to confirm contamination free operation during the test. Another problem was that PCR didn't differentiate between viable and non viable bacteria. The unstable nature of virulence plasmid (Bhaduri et al.,1991 and Kwaga and Iverseng, 1991) complicated the isolation of plasmid bearing virulent $Y$. enterocolitica. The overgrowth of virulent cells eventually leading to completely avirulent culture (Toora et al., 1994). 
The correlation between the virulence tests and PCR results for the presence of vir $F$ gene. From the tested $10 Y$. enterocolitica isolates, 3 strains of serobiotypes $0: 3 / 2(2)$ and $0: 9 / 2(1)$ were positive virulence in all virulence characteristics including heat stable enterotoxin production (ST) and Congo red magnesium oxalate (CRMOX). While they were negative for Sereny test (GPC), Aesculin hydrolysis (AH), Salicin fermentation (SF) and Pyrazinamidase production (pp), they were also positive for the presence of virF gene.

On the other hand,three isolates of serobiovar O:3/2 were positive for virulence characteristics of ST and CRMOX but negative for GPC, $\mathrm{AH}, \mathrm{SF}$ and PP, while non of them possessed the vir F-gene. 2 strains of serobiovars $0: 5 / 2$ and $0: 9 / 2$ showed positive results for all the virulence tests except for GPC,SF and PP were negative and vir F gene was not identified in any of them. One isolate of serobiotype $\mathrm{O}: 3 / 2$ was CRMOX+ and it was negative for ST, GPC, AH,SF, PP, and not possessed vir $\mathrm{F}$ gene.At the same time one isolate of bioserotype 0:5/2 was positive only for CRMOX test and negative for other examined virulence tests and/also it was negative for vir $F$ gene. These findings were agree with Bhaduri et al., (1997) who found that virulent plasmidbearing clones of $Y$. enterocolitica (YEP+) were recovered from both artificially contaminated group pork and naturally contaminated tongues expressed plasmid-associated virulence characteristics, including colonial morphology (appearance of small sized colonies of 1.13 $\mathrm{mm}$ ), CV binding (appearance of dark violet colony) L or low calcium medium (appearance of pin point colonies $0.36 \mathrm{~mm}$ ), CR uptake (appearance of red pin point colonies). The mouse virulence test of 
YEP+ isolates was positive for all examined samples, also they confirmed $\mathrm{CR}+$ colonies of $Y$. enterocolitica by multiplex PCR. Using the chromosomal ail gene (attachment-invasion locus) and vir $F$ gene (transcriptional activator for the expression of plasmid encoded outer membrane protein yop.51) from the virulence plasmid. The primer pairs were used (5'-TCA TGG CAG AAC AGC AGTGAG-3' and 5'-ACT CATCTT ACC ATT AAG AAG-3') for detection of the vir $F$ gene (430to 1,020-nucleotide region) amplified a 591-bp product from the virulence plasmid.The authors suggested that the irgasan suppress the growth of pure cultures YEP+ when addaed at the onest of growth and didn't when added after the lag phase, thus they eliminated it from initial enrichment medium. It was found that addition of igrasan at $24 \mathrm{~h}$ have the best recovery of YEP+ colonies. This timing may reduce the inhibitory effect of the antibiotic. They also added, both CIN and MacConkey's agar were used for presumptive isolation YEP+ strains.CIN agar didn't prove to be effective in isolating colonies that were eventually shown to be YEP+ strain due to antibiotic content of CIN agar may diminish the viability of YEP+ strains. On the other hand, MacConkey's agar gave consistently higher number of presumptive which were eventually shown to be YEP+ strains. $10 \%$ of presumptive $Y$. enterocolitica from MacConkey's agar was found to comprise YEP+ strains.

In the present work, although the examined virulence characteristics, the low number of $Y$. enterocolitica isolates ( 3 out of 10) possessed the virF gene were obtained. This may be related to using of irgasan which was added to the CIN medium at initial step of isolation of strains from examined samples and not after the lag phase as described 
by Bhaduri et al., (1997) and this may lead to lose of plasmid. Moreover, culturing at $37^{\circ} \mathrm{C}$ and prolonged storage of $Y$. enterocolitica can result in loss of the virulence plasmid or these isolates may lost its virulence plasmid during boiling for preparation of DNA for PCR as mentioned by Kaneko et al., (1995).

In Egypt, Gad El-Said et al., (1996) examined blood samples from apparently healthy cattle, buffaloes and sheep for agglutination. $43 \%$ reacted strongly for antibodies of serovars O: 3 and/ or O: $9.41 \%$ were positive for $Y$. enterocolitica after elimination of 8 sera samples which gave cross reactivity with B.abortus. Antibody prevalence was the highest in buffaloes and sheep (46\% for each), while cattle $37 \%$ were positive. That's in agreement to great extent with our above results. Tha same results were observed by Hurvell and Lindberg (1973), Mittal and Tizard (1981) and Chen et al., (1983).

Our obtained results showed that PCR was the most accurate rapid and a simple assay for detection of $Y$. enterocolitica and save time consumed for diagnosis, these findings were agree with Zheng et al., (2008), Lambertz et al., (2008) and Zheng et al.,(2007) who reported that the detection of $Y$. enterocolitica is higher in PCR than culture method.

Concerning sensitivity test of the isolated $Y$. enterocolitica strains, reveal that amikacin and Gentamycin were the most effective antibiotics against all tested strains followed by cefotaxime and ofloxacin. These findings were in agreement with Baumgartnera et al., (2007) and Zheng et al., (2008) who proved that amikacin, gentamycin and cefotaxime were highly effective against $Y$. enterocolitica isolated followed by ofloxacin. 


\section{REFERENCES}

- Adesiyun A.A.; Kaminjolo J.S. and Loregnard R. (1992) : Frequency of isolation of $Y$. enterocolitica from livestock in Trinidad. Vet. Rec., $131(22): 516$.

- Ahmed A.O.(1998): A note on relationship between Yersinia groups and Brucella groups of microorganisms. M.V.Sc. thesis (Microbiology), Faculty of Veterinary Medicine, Cairo University.

- Ahmed A.O (2003): The role of Y.enterocolitica in enteric diseases of cattle, sheep and goats. Ph.D.Thesis (Microbiology). Faculty of Veterinary Medicine, Cairo University.

- Ahovonen, P. (1972): Human yersiniosis in finland.I.Bacteriology and serology. Ann, Clin. Res., 4:30-38.

- Ahovonen P. and Sievers K.C. (1969): Yersinia enterocolitica infection associated with Brucella agglutinins. Clinical features of 24 patients. Acta Med.Scad. 185: 121-125.

- Ahovonen P.; Thal E. and Vasenius H.(1973): Occurrence of $Y$. enterocolitica in animal in Finland and Sweden. Microbiol. Immunol., 2: 135-136.

- Alonso J.M.; Bercovier H.; Servan J and Mollaret H.H. (1979): Contribution to the study of the ecology of $Y$. enterocolitica in France. Cont.Microbiol., Immunol. 5: 132-143.

- Bailey W.R. and Scott E.G. (1986): Diagnostic Microbiology. 7 th ed. C.V. Mosby Co.USA. 
- Baumgartnera A.; Kuffer M.; Suter D.; Gemmi T. (2007): Antimicrobial resistance of $Y$. enterocolitica. Int. J. Food Microbiol., 115 (1): 110-114.

- Bercovier H. and Mollaret H.H. (1984): Genus XIV. Yersinia vanloghem. pp. 498-506. In Kreig N.R. and Halt J.G.(eds.) Bergey's Manual of Systemic Bacteriology, Vol. 1 Williams and Wilkins, Baltimore.

- Bercovier H.; Brenner D.J.; Ursing J.; Steigervvalt A. G.; Fanning G.R.; Alonso J.M.; Carter G.P. and Mollaret H.H. (1980): Characterization of $Y$. enterocolitica sensu stricto. Curr.Microbiol., 4: 201-206.

- Bhaduri S.; Cottrell B. and Allan R.R. (1997): Use of a single procedure for selective enrichment, isolation and identification of Plasmid-Bearing Virulent $Y$. enterocolitica of various serotypes from pork samples. Appl. Environ.Microbiol., 63 (5): 1657-1660.

- Bhaduri S.; Turner- Jones C. and Lachica R.V. (1991): Convenient aearose medium for the simulataneous determination of low calcium response and Congo red binding by virulent strains of $Y$. enterocolitica. J. Clin. Microbiol., 29: 2341-2344.

- Bin Kun H.; Sheng D.E.; Hong B.O.; Shixian G.Z. and Slee K.J. (1994): Yersiniosis in sheep due to $Y$. enterocolitica. Br.Vet. J., 150: 473-475.

- Bottone E.J. (1997): Y. enterocolitica overview and epidemiologic correlates. Microbes and Infection, 1: 323-333. 
- Brenner D.J.; Hickman F.W.; Asbury M.A. and Steigerwalt A.G. (1977): Taxonomic and Nomenclature changes in Enterobacteriaceae. HEW Publication no. (CDC) 78-8356. US. Department of Health, Education and Welfare, Atlanta Ga.

- Brewer R.A. and Corbel M.J. (1983): Characterization of Y. enterocolitica strains isolated from cattle, sheep and pig in the United Kingdom. J.Hyg. 90 (3): 425-433.

- Chen M.G.; Zeng G.J.; Sun Y.Q.; Xia Q.L.; Zhang B.H. and Zhong J. (1983): Survey of antibody levels against $Y$. enterocolitica infection in pigs. Chinese J.Vet. Med., 9(12): 12-14.

- Christensen S.G. (1980): Y. enterocolitica in Danish pigs. J. Appl. Bacteriol. 48: 377-382.

- Corbel M.J.; Brewer R.A. and Hunter D. (1990): Characterization of $Y$. enterocolitica associated with ovine abortion. Vet.Rec.127: 526527.

- Cornells G.R. (1994): Yersinia pathogenicity factors. Curr.Trop. Microbiol, Immunol.192. 243- 263.

- Cruickshank R.; Dugid J.P.; Marmion B.P. and Swain R.H.A. (1975): Medical Microbiology $12^{\text {th }}$ ed. Churchill livingstone Edinburgh, London and New York.

- Davey G.M.; Bruce J. and Drysdale E.M. (1983): Isolation of Y. enterocolitica and related species from the feces of cows. J.Appl.Bact.55: 439-443.

- Delor J. and Cornell's G. (1992): Role of YST toxin in experimental infection of young rabbits. Infect. Immun.10: 4269-4277. 
- Delor L.; Kaeckenbeek A.; Wauters G. and Cornelis G.R. (1990): Nucleotide sequence of YST. The $Y$. enterocolitica gene encoding the heat stable enterotoxin, and prevalence of the gene among pathogenic and non pathogenic Yersinia. Infect. Immun.58:2983-2988.

- Falcao J.P.; Brocchi M.; Proneaca- Modena J.L.; Acrani G.O.; Corea E.F. and Falcao D.P. (2004): Virulence characteristics and epidemiology of $Y$. enterocolitica and Yersinia other than $Y$. pseudotuberculosis and $Y$. pestis isolated from water and sewage. J.Appl. Microbiol., 96:1230-1236.

- Fantasia M.; Mingrone M.G.; Marini A.; Boscato U. and Crolti D. (1993): Characterization of Yersinia species isolated from cattle and pig farms. Vet. Rec, 22: 532-534.

- Farmer J.J.; Carter G.p.; Miller V.L.; Falkow S. and Wachsmuth I.K. (1992): Pyrazinamidase, CRMOX agar, Salicin fermentationEsculin hydrolysis and D-xylose fermentation for identifying pathogenic serotypes of $Y$. enterocolitica. J. Clin. Microbiol., 30(10): 2589-2594.

- Feng P. and Weagant S.D. (1994): Yersinia In Food Borne Disease Handbook, Vol. 1, ed. Hui, Y.H., Gorham, J.R., Man-ell, K.D. and Oliver, D.O. pp 427-460. New York: Marcel Dekker.

- Finegold S. and Martin W. (1982): Diagnosis Microbiology. $6^{\text {th }}$ Ed., The C.V. Mosby Co., St. Louis, Toranto, London.

- Filetici E.; Anastasio M.P.; Pourshabon M. and Fantasia M. (2000): Genotypic and phenotypic characteristics of Yersinia spp. Isolates from food and man. Food Microbiol., 17:261-267. 
- Fredriksson-Ahomaa B.j.; Hielm S. and Korkeala H. (1999): Prevalence and characterization of pathogenic $Y$. enterocolitica in pig tonsils from different slaughter houses. J. food Prot., 62(2): 123-127.

- Fukushima H. and Gomyoda M. (1986): Growth of Y. tuberculosis and $Y$. enterocolitica biotype 3B serotype $\mathrm{O} 3$ inhibited on cefsulodinIrgasan-novobiocin agar. J.Clin.Microbiol., 24(1) 116-120.

- Fukushima H.; Hoshina K. and Gomyoda M. ( (1993): Selective isolation of pathogenic $Y$. enterocolitica from pork using Hela cell lines. In Proceedings, II The International Symposium of The World Association of Veterinary Food Hygienists, 24-29 October 1993, Bangkok, Thialand (WAVFH) 509-511.

- Gad El-Said W.A.; El-Danaf N.A.; Tanios A.I.; Shaaban A.I. and Rashed M.E. (1996): Seroprevalence of Y. enterocolitica O:3 and/or O:9 in animals in Egypt with reference to its serological crossreactions with Br. abortus. Vet. Med.J. (3): 629-635.

- Gemski P.; Lazere J.R. and Casey T. (1980): Plasmid associated with pathogenicity and calcium dependency of $Y$. enterocolitica. Infect.Immun. 27: 682-685.

- Greenwood M.H. and Hooper W.L. (1988): The use of alkalinity and incubation at $9 \mathrm{C}$ for improved recovery of Yersinia spp from feces.Epid. Inf., 101 (1): 53-58.

- Hoorfar J. and Holmvig B.F. (1999): Evaluation of culture methods for rapid screening of swine fecal samples for $Y$. enterocolitica $\mathrm{O}: 3 /$ biotype 4. J. Vet. Med.B. 46: 189-198. 
- Hurvell B. and Lindberg A.A. (1973): Serological cross reactions between different immunological studies on phenol water extracted lipopolysaccharides from $B r$. abortus and $Y$. enterocolitica type IX. Acta path. Microbiol, Scand., 81:113-119.

- Hussein H.M.; Fenwick S.C. and Lumsden J.S. (2001): A rapid and sensitive method for the detection of $Y$. enterocolitica strains from clinical samples. J.Appl. Microbiol., 33 (6): 445-449.

- Isberg R.R. (1990): Pathways for the penetration of enteroinvasive Yersinia into mammalian cells. Mol.Biol. Med., 7:73-82.

- Kandolo K. and Wauters G. (1985): Pyrazinamidase activity in $Y$. enterocolitica and related organisms. J. Clin.Microbiol., 21: 980-982.

- Kaneko S.; Ishizaki N. and Kokubo Y. (1995): Detection of pathogenic $Y$. enterocolitica and $Y$. pseudotuberculosis from pork using Polymerase chain reaction. Contrib. Microbiol., Immunol. 13: 153-155.

- Kapperud G.(1991): Y. enterocolitica in food hygiene. Int.J.Food Microbiol., 12:53-66.

- Kay B.A.; Wachsmuth P.I.K.; Gemski P.; Feely J.C.; Quan T.J. and Brenner D.J. (1983): Virulence and phenotype characterization of $Y$. enterocolitica isolated from humans in the United State. J.Clin.Microbiol., 17:128-138.

- Knapp W. and Thai E. (1973): Differentiation of Y. enterocolitica by biochemical reactions. Cont. Microbiol., Immunol.2: 10-16.

- Kocagoz T.; Yilmaz E.; Ozkara S.; Kocagoz S.; Hayran M.; Sachedeva M. and Chambevs H.F. (1993): Detection of Mycobacterium tuberculosis in sputum samples by polymerase chain reaction using a simplified procedure. J. Clin. Microbiol., 31(6): 14351438. 
- Kwaga J.K. and Iverseng J.O. (1991): Laboratory investigation of virulence among strains of $Y$. enterocolitica and related species from pigs and pork products. Cand.J.Microbiol., 38: 92-97.

- Lambertz S.T.; Nilsson C. and Lindblad N. (2008): Real time PCR method for detection of pathogenic $Y$. enterocolitica. Appl. Environ.Microbiol., 74 (19): 6060-6067.

- MacFaddin J.F. (1976): Biochemical Tests for identification of Medical Bacteria. $1^{\text {st }}$ Ed., Williams and Wilkins, Baltimore, USA.

- Miller V.I. And Falkow S. (1988): Evidence for two genetic loci of $Y$. enterocolitica that can promote invasion of epithelial cells. Infect. Immun. 56: 1242-1248.

- Mittal K. R. and Tizard I.R. (1981): Serological cross- reaction between $B r$. abortus and $Y$. enterocolitica O:9 serological response. Am. J.Vet. Res., 41 (10): 1607- 1610.

- Morris G.K. and Feeley J.C. (1976): Y. enterocolitica : A review of its role in food hygiene. Bull. WHO, 54: 79-85.

- Nakajima H.; Inoue M., Mori L.; Itoh K.I. and Watanabe H. (1992): Detection and Identification of $Y$. pseudotuberculosis and pathogenic $Y$. enterocolitica by an improved PCR method. J. Clin.Microbiol., 30: 2484-2486.

- Nilehn B. (1969a): Studies on Y. enterocolitica with special references to bacterial diagnosis and occurrence in human acute enteric disease. 1- Characterization of $Y$. enterocolitica strains of human origin and their relation to strain of various animal origin. Acta. Path. Microbiol., Scand. Suppl. 206: 1-48. 
- Nilehn B. (1969b): Studies on $Y$. enterocolitica growth on various solid media at 37C and 25C. Acta. Path. Microbiol., Scand. 77: 685697.

- Okoroafor A.A.; Adesiyun A.A. and Agobnlahor D.E. (1988): Prevalence and characteristics of $Y$. enterocolitica strains isolated from pigs in Jos, Nigeria. Br.Vet.J.144:131-138.

- Pai C.H. and Mors V. (1978): Production of enterotoxin by $Y$. enterocolitica. Infect. Immunol., 19: 908-911.

- Pedersen K.B. (1979): Occurrence of Y. enterocolitica in the throat of swine. Contrib. Microbiol., Immunol. 5: 253-256.

- Pianetti A.; Bruscolini F.; Baffone W.; Brandi G.; Salvagglo L.; Biffi M.R. and Albavo A. (1990): Y. enterocolitica and related species isolated in the Pesaro and Urbino area (Italy) from 1981 to 1986. J. Appl. Bact., 68: 133-137.

- Prpic J.K.; Robins-Browne R.M. and Davey R.B. (1983): Differentiation between virulent and avirulent $Y$. enterocolitica isolated by using congo red agar. J.Clin. Microbiol., 18(3): 468-490.

- Riley G. and Toma S. (1989): Detection of pathogenic $Y$. enterocolitica by using Congo Red Magnesium Oxalate agar medium. J. Clin.Microbiol., 27(1): 213-214.

- Robins-Browne R.M.; Takeda T.; Fasano A.; Marie A.B.; Dohi S.; Kasuga H.; Fong G.; Prado V.; Guerrant R.L. and Morris, G. (1993): Assessment of enterotoxin production by $Y$. enterocolitica and identification of a novel heat stable enterotoxin produced by a noninvasive $Y$. enterocolitica strain isolated from clinical material. Infect. Immun.61 (2):764-767. 
- Schiemann D.A. (1979): Synthesis of selective agar medium for Y. enterocolitica. Cand. J. Microbiol., 25: 1298- 1304.

- Schiemann D.A. and Devenish J. A. (1982): Relationship of Hella cell infectivity to biochemical, serological and virulence characteristics of $Y$. enterocolitica. Infect. Immun., 35(2): 497-506.

- Staak C.; Draeger A.; Bahn P. and Nockler K. (2000): Contribution to the differentiation of cross-reacting antibodies in brucellosis serology. 1- Reaction with various Yersinia serotypes and antibody avidity. Berl. Munch. Tierarztl. Wochenschr, 113(10): 361-367.

- Tanios A.I. (1994): Carnage of Y. enterocolitica: A prospective study of bacteriological and serological features. Ph. D. Thesis (Microbiology), Faculty of Vet. Medicine, Cairo University.

- Tauxe R.V.; Vandepitte J.; Wauter G.; Martin S.M.; Goossens V.; De Mol P.; Van Noyen R.; and Thieis G (1987): Y. enterocolitica infection and pork: the missing link. Lancet, I(8542): 1129-1132.

- Thisted-Lambertz S.; Ballagi-Pordany A.; Nilson A.; Norberg P. and Danielsson-Tham M.L. (1996): A comparison between a PCR method and a conventional culture method for detecting pathogenic $Y$. enterocolitica in food. J.Appl. Microbiol., 81:303-308.

- Toora S.; Singh G.; Tiwari R.P. and Singh G. (1994): Drug resistance and lecithinase activity of $Y$. enterocolitica isolated from buffaloes milk . Int. J. Food Microbiol., 9: 167-171. 
- Winblad S. (1967): Studies on serological typing of $Y$. enterocolitica. Acta Path. Microbiol., Scand., Suppl. 187: 115. Cited in Vet. Bull., 51(7): 501-505.

- Winblad S.; Nilehn B. and Sternby N.H. (1966): Y. enterocolitica, Pasteurella $X$ in human enteric infections. Br.Med.J., 2: 1363-1366.

- Wren B.W. and Tabaqchali S. (1990): Detection of pathogenic Y. enterocolitica by PCR. Lancet 336: 693.

- Zamora J.; Reinhardt G.; Polette M.; Macias P. and English J. (1997): Isolation of $Y$. enterocolitica and $Y$. kristensenii from ovine feces. Arc. Med. Vet. 29 (2): 301-305.

- Zheng H.; Sun Y.; Lin S. and Mao Z. (2008): Y. enterocolitica infection in diarrheae patients. Eur.J. Clin. Microbiol. Infect. Dis.,27(8): 741-752.

- Zheng H.; Wang J.; Sun Y. and Jiang B. (2007): Clinical isolation and characterization of $Y$. enterocolitica in China. Digestion, 75 (4): 199-204.

- Zheng X.B. (1987): Isolation of $Y$. enterocolitica from feces of diarrhoeic swine. J. Appl. Bact. 62 (6): 521- 525.

- Zheng X.B. and Xie C. (1996): Note: Isolation, characterization and epidemiology of Y. enterocolitica from humans and animals. J. Appl. Bact. 81: 681-684. 